\title{
Telecommunication, Media and Internet Techno-Economics
}

\author{
Carmen Mas Machuca ${ }^{1}$
}

Accepted: 4 May 2017 / Published online: 17 May 2017

(C) Springer Science+Business Media New York 2017

The 12th International Conference of Telecommunication, Media and Internet Techno-Economics (CTTE) was held in Munich, Germany, on November 9th-10th 2015. The event was organized by the Technical University of Munich (TUM). It was technically co-sponsored by the IEEE Germany Section.

CTTE is a well-established event focusing on original and fundamental concepts and studies in the field of telecommunications, internet and media techno-economics. It also serves as a forum for communication among researchers and practitioners working in a wide variety of scientific areas with a common interest in improving techno-economics and advanced telecommunications internet and media services.

The keynote talk was given by Dr. Prinz who leads the FttB development of the Stadtwerke München (SWM) in Munich, Germany. The title of the talk was "Research meets practise-How a large project promotes innovation."

This issue is a special issue of selected papers from the CTTE. It consists of four papers addressing different economic aspects of communication networks.

The first paper by P. Maillé and B. Tuffin entitled "Preventing competition using side payments: when non-neutrality creates barriers to entry" addresses network neutrality and the effects of side payments through economic modeling. The paper investigates the conditions under which the incumbent can benefit from such a barrier-to-entry, and the consequences of that strategic behavior on the other actors: content providers, users, and the internet service providers.

The paper by E. Grigoreva et al. entitled "Techno-economic case study on dedicated RAN for an intelligent transportation system: impact of the legislation-driven costs" performs a techno-economic evaluation of four communication technologies

Carmen Mas Machuca

cmas@tum.de

1 Technical University of Munich, Chair of Communication Networks, Arcisstraße 21, 80333 Munich, Germany 
that can be used in intelligent transportation systems: Ultra high frequency standard, Wi-Fi 802.11n, dedicated short range communications (DSRC) 802.11p and LTE. Radio access network planning and legislation-driven cost influences on cost for DSRC and LTE deployments are also discussed.

The paper entitled "Internet service provision and content services: paid peering and competition between Internet providers" authored by A. Gaivoronski et al. presents modeling tools for the evaluation of business models of Internet Service Providers. The tools have been applied to two potential cash flows: paid peering and service differentiation. Results of these two models are analyzed in detail.

Finally, the paper by R. Romero Reyes and T. Bauschert entitled "Bottom-up framework for cost allocation to services in telecommunication networks; Case study: cost allocation for flex-grid optical networks" proposes a bottom-up total cost of ownership (TCO) calculation framework to the services supplied by a communication service provider. The framework allows differentiating stand alone, fully allocated and long-run incremental costs of a service. The framework is applied to an operator offering transport services using an optical network and comparing fixed-grid with flex-grid solution.

We hope that the readers from both academia and industry will find this issue interesting and relevant to their needs. We would like to address special thanks to the reviewers for the constructive and insightful reviews as well as to Prof. Voß, Editor-in-Chief of this journal for his support in preparing this issue. 